This item was submitted to Loughborough's Research Repository by the author.

Items in Figshare are protected by copyright, with all rights reserved, unless otherwise indicated.

\title{
Police interviews with vulnerable people alleging sexual assault: probing inconsistency and questioning conduct
}

\section{PLEASE CITE THE PUBLISHED VERSION}

http://dx.doi.org/10.1111/josl.12124

\section{PUBLISHER}

(c) Wiley

\section{VERSION}

AM (Accepted Manuscript)

\section{PUBLISHER STATEMENT}

This work is made available according to the conditions of the Creative Commons Attribution-NonCommercialNoDerivatives 4.0 International (CC BY-NC-ND 4.0) licence. Full details of this licence are available at: https://creativecommons.org/licenses/by-nc-nd/4.0/

\section{LICENCE}

CC BY-NC-ND 4.0

\section{REPOSITORY RECORD}

Antaki, Charles, Emma Richardson, Elizabeth Stokoe, and Sara Willott. 2019. "Police Interviews with Vulnerable People Alleging Sexual Assault: Probing Inconsistency and Questioning Conduct”. figshare. https://hdl.handle.net/2134/18013. 
Police interviews with vulnerable people alleging sexual assault: probing inconsistency and questioning conduct

ACCEPTED FOR PUBLICATION Journal of Sociolinguistics, 2015

Charles Antaki, Emma Richardson, Elizabeth Stokoe

Dept of Social Sciences

Loughborough University

Loughborough

LE11 3TU

UK

and

Sara Willott

Birmingham Community HealthCare NHS Trust

Learning Disability, Psychology Services

The Greenfields, 30 Brookfield Road

Kings Norton

Birmingham B30 3QY

UK 
Police interviews with vulnerable people alleging sexual assault: probing inconsistency and questioning conduct

\section{Revision 2}

\section{Abstract}

Reporting sexual assault to the authorities is fraught with difficulties, and these are compounded when the complainant is hindered by an intellectual disability (ID). In a study of $19 \mathrm{UK}$ police interviews with complainants with ID alleging sexual assault and rape, we found that most interviewing officers on occasion pursued lines of questioning which not only probed inconsistencies (which is mandated by their guidelines), but implicitly questioned complainants' conduct (which is not). We detail two main conversational practices which imply disbelief and disapproval of the complainants' accounts and behaviour, and whose pragmatic entailments may pose problems for complainants with ID. Such practices probably emerge from interviewers' foreshadowing of the challenges likely to be made in court by defence counsel. As a policy recommendation, we suggest providing early explanation for the motivation for such questioning, and avoiding certain question formats (especially how come you did $X$ ? and why didn't you do $Y$ ?). 


\section{Introduction}

Victims of sexual assault and rape face grave problems in bringing their case to the authorities, and seeing their ordeal end in a successful court prosecution. The literature documenting this state of affairs is a large one, for which there is here only space but a cursory account; but recent reports (e.g. Spohn and Tellis, 2014) only confirm the difficulties identified in classic studies (e.g. Frohmann, 1991): those alleging sexual assault and rape - overwhelmingly, women - face shame, fear of retribution, fear of disbelief, police tardiness, and, as Ehrlich (2001) documents, a pervasive battle against culturally-held doubts that bedevil their credibility. Indeed Macleod (2010) identifies the operation of 'rape myths' even in the police interviews of women complainants at the very earliest stages of investigation.

Against this background, the experiences of people with an intellectual disability are still more concerning. They are disproportionately likely to be victims of violence (US Bureau of Justice Statistics, 2014) and sexual abuse (McEachern, 2012). Moreover, after the event they are likely to suffer "marked increases in the frequency and severity of emotional, physiological and behavioural symptoms of psychological distress" according to Rowsell, Clare and Murphy (2013, p 257). Despite efforts to change legal processes, research suggests that people with intellectual disabilities continue to find that even their well-evidenced cases are not pursued in the criminal justice system, and that adult rape victims with learning disabilities or psychiatric problems are over-represented in terms of cases that drop out of the system (Lea et al., 2003).

In this article we concentrate on a potential blockage in an early part of the process in the victim's potential route through the criminal justice system in England and Wales - namely, their first recorded interview with the police. It is here that the person with ID will, because of their difficulties with communication and social functioning, face difficulties over and above those faced by people with typical mental capacity. By definition (either via the Diagnostic and Statistical Manual of Mental Disorders (DSM), or the more global International Classification of Diseases (ICD)), to be diagnosed as having intellectual disabilities is to be deficient in mental capacity for language, 
memory, and comprehension, and to be impaired in the ability to make social judgements, empathise, and understand others' points of view. Those two aspects of mental functioning come together in the person's pragmatic understanding - working out what people mean by non-literal expressions, indirect questions, or other formulations that require an understanding of others' perspectives (see Perkins, 2010 on pragmatic impairment generally). All of these elements will necessarily be present in the demands of a police interview.

Given the centrality of the interview, and the special difficulties of comprehension and memory experienced by people with ID, one of the recommendations of the Royal College of Psychiatrists' (2014) report on the involvement of adults with intellectual disability in the criminal justice system is that "all police officers, in particular custody officers and community support officers, need to have intellectual disability awareness training as part of their induction process. This training should be provided with input from health professionals." (2014 p. 11). The main instrument for such training and guidance given to police interviewers in England and Wales is set out in Achieving Best Evidence in Criminal Proceedings: Guidance for Vulnerable or Intimidated Witnesses, including Children (henceforth $A B E$ ) published by the Ministry of Justice (2011). Until now, no research as been carried out into exactly how, and to what extent, police officers follow $A B E$ guidance for witnesses and complainants in general, let alone when the witness or complainant has an intellectual disability.

Our interest is in how the officers adhere to, or depart from, the guidelines laid out in the national guidelines Achieving Best Evidence, and our specific focus will be on the way in which they challenge inconsistent or otherwise questionable aspects of the interviewee's account.

\section{DATA}

Our data come from a police force in England. 20 interviews from archived cases were made available to us as being representative of people with "learning disabilities" (the force's term) who had reported sexual assault or rape. The interviews were recorded between 2010 and 2013, in one city station, 
by different officers. Interviews lasted between 21 minutes and just over 2 hours. Nineteen of the 20 tapes could be analysed. Of these 19 cases, 10 alleged rape and the rest sexual assault. Internal evidence from the tapes showed that two of the complainants were children under 16 ( 1 male and 1 female); 14 were young women, and one a mature woman; and two were men (one young and one young-middle aged ). The archived records made available to us included two additional pieces of information accompanying each videotape: a description of the complainant's intellectual impairment, and a note of the way that the case was resolved. Both were brief. Examples, respectively, in full, are "Learning difficulties. Deaf." and "Filed undetected. No CPS". Three of the cases led to a court case, two resulting in a guilty verdict. The tapes were visually and aurally anonymised before leaving the police station.

\section{ANALYSIS}

The conduct of the interview

As the $A B E$ guidelines recommend, our recordings show that the interview itself normally falls into four distinct phases, beginning with an initial orientation to the nature of the interview. The second, and often most substantial, phase is taken up with the interviewer soliciting the interviewee's account of events in a free narrative. The next, probing, phase is more clearly interviewer-led, with the officer checking aspects of the interviewee's account. The last phase, which may be quite short, is the termination of the interview. In this article, we shall be concentrating on the probing phase, where the bulk of the challenging questions appear.

The key to our analysis is a comparison of the practices recommended in the guidelines of Achieving Best Evidence and the actual practices of the interviewing officers, with a special focus on formats of questioning that may present special pragmatic difficulties to people with the deficits associated with intellectual disability.

$A B E$ lays out the full range of issues involved in managing interviews with suspects and witnesses. It should be noted that the tone of $A B E$ throughout is 
concerned for witnesses' well-being during the interview ( as expressed in section 2.230: "throughout the interview, the interviewer should convey to the witness that they have respect and sympathy for how the witness feels"), and respectful of witnesses' good faith. Save for a brief section (2.144) on overtly hostile witnesses (e.g. those themselves involved in the offence, or closely related to the alleged offender), the major difficulties it foresees with witnesses' accounts is inconsistency and omission (sections 2.161 to 2.167) caused by anxiety, memory problems, comprehension difficulties, inappropriate questioning or other innocent reasons. Hence its recommendations for probing are couched in terms of understanding or clarifying what witnesses say; not in challenging their veracity, still less questioning the advisability of the conduct they report.

The two sections most pertinent here are section 3.67 and 3.68 on inconsistencies in interviewees' accounts.

\section{Inconsistencies}

3.67 Witnesses can on occasion provide misleading accounts of events; these are often the result of misunderstandings or misremembering rather than deliberate fabrication. The most common cause of these misunderstandings is the interviewer failing to ask appropriate types of question or reaching a premature conclusion that the interviewer then presses the witness to confirm.

3.68 Where there are significant inconsistencies in the witness's account interviewers should explore them after they have probed their basic account. Witnesses should only be challenged directly over an inconsistency in exceptional circumstances and even then only when it is essential to do so. Rather, such inconsistencies should be presented in the context of puzzlement by the interviewer and the need to be quite clear what the witness has said. On no account should the interviewer voice their suspicions to the witness or label a witness as a liar: there may be a perfectly innocuous explanation for any inconsistency. [Achieving Best Evidence in Criminal Proceedings, emphasis added]

Although the aim and sentiments of the guidelines are to steer the interviewer away from sounding suspicious or implying that the witness is lying, there is, inevitably, no specific script it can offer. The interviewer is left to her or his own competence as a native speaker, and whatever training he or she has had in the 
actual delivery of such interviews. But that competence and training may or may not be sensitive to the pragmatic capacities of the interviewee with ID.

We begin the analysis with an example of a probe that is in fact consistent with the guidelines, and does manage to use a format that avoids suspicion and challenge.

\section{A probe in line with $A B E$ recommendations}

$\mathrm{ABE}$ recommends sparing use of probes, and, if used, that they be phrased in the form of the interviewer seeking to clarify inconsistencies and improve their own understanding of the matter. Here is an example that matches the recommendation:

\section{Extract 1 WMP3 Pulled dress up}

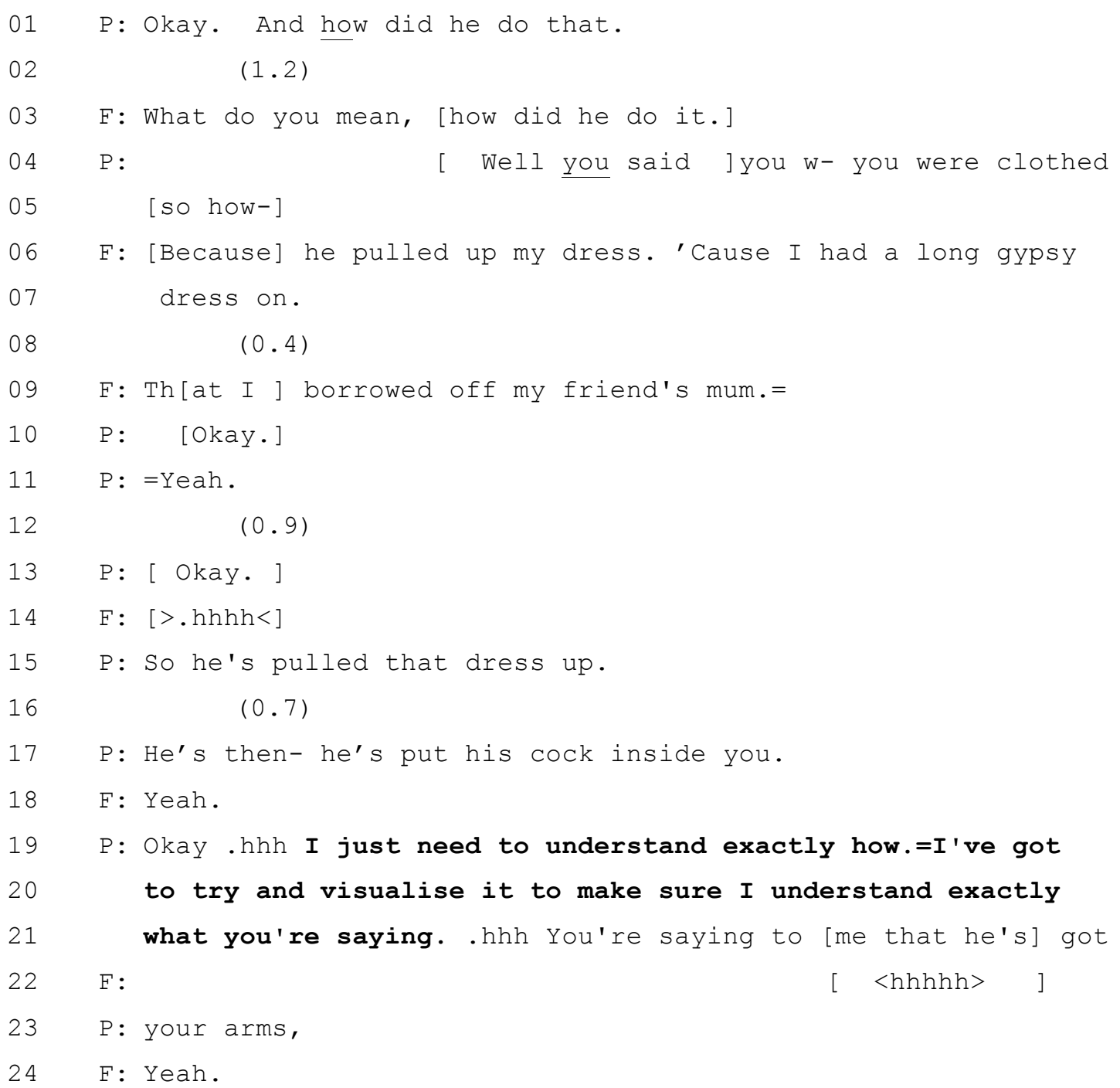


In Extract 1 above, the interviewer is attempting to clarify an important forensic issue which has been clouded by a possible physical inconsistency (the victim's "being clothed", yet the rapist managing to insert his penis into her vagina). She does so by appeal to her (the interviewer's) own need to "understand exactly how" and her "[trying] to visualise it to make sure I understand exactly what you're saying" (bolded lines). This is consistent with the $A B E$ recommendation that "inconsistencies should be presented in the context of puzzlement by the interviewer and the need to be quite clear what the witness has said". This recommendation was adhered to in most of the questions, in all of the interviews. However, there were also significant departures from the recommendations in most of the interviews, and it is these that form the bulk of our analysis.

2. Probes implying a fault or problem with the complainant's account. Inspection of the videotapes revealed that the interviewer sometimes departed from $A B E$ recommendations in two ways, both implying fault:

a) they probed physical details, chronology and so on, in a manner that implied not that the interviewee's account was correctable, but paradoxical or implausible; or

b) they probed the complainant's behaviour, choices or decisions in a way that that implied that they had done something questionable (inappropriate, illadvised, poorly judged and so on), or more frequently, failed to do something sensible in the circumstances (appropriate, , expectable, responsible, prudent and so on).

It may be that these challenging questions are routinely asked of any complainant; the point we want to stress is that they have complex pragmatic implications which are hard for a person with an intellectual disability - they require processing of more than the surface value of the utterance, as we shall see.

We base our claim that the probe requires the processing of implied fault (be it either in the implausibility of the stated events, or the imprudence of the stated behaviour) on two grounds. The first is the pragmatic force of the question 
formats, which would be recognised intuitively by speakers familiar with English usage, and is backed by evidence from consideration of how the formats are used in normal practice (see, for pragmatics methodology in general, Allen and Jaszczolt, 2012). The second is interactional - that is, how the participants in the scene treat the questions: in the first instance, the reaction of the interviewee, and then the subsequent questions by the interviewer (for the interactional approach as handled by Conversation Analysis, see, for example, Sidnell, 2010).

A. Probes implying physical implausibility in the interviewee's account. In these cases, the interviewer uses a questioning format that requires the interviewee to see, and handle, the pragmatic implication that there is something notably implausible in the physical details of the interviewee's account - that is, two elements of the scene that appear to be (or can be construed as being) logically or physically paradoxical.

The formats that tend to this reading begin with the interviewer establishing that the interviewee asserts a certain state of affairs, and then issuing a question about a further, and implicitly contradictory, detail. This question would use some variety of a how (and less frequently a why) interrogative, with or without an implicit or explicit conditional connective (e.g. if), a consequential connective (e.g. so), or the contrastive though; and with the focus of the interrogative being the physical or logical possibility of a given further event or detail:

- If $x$ was the case, how was Y possible? Such a question pragmatically implies implausibility.

- how was $X$ the case, though? Implies that the explanation already given has not been adequate given the circumstances established

- so how did X happen? The turn-initial 'so' here is equivalent to 'given what you have just said', and implies that there is a notable contradiction

Example 2 below illustrates the sequence of the interviewer first establishing a state of affairs, then contrasting it in an interrogative that implied implausibility. 
Extract 2 WMP 3 Holding you

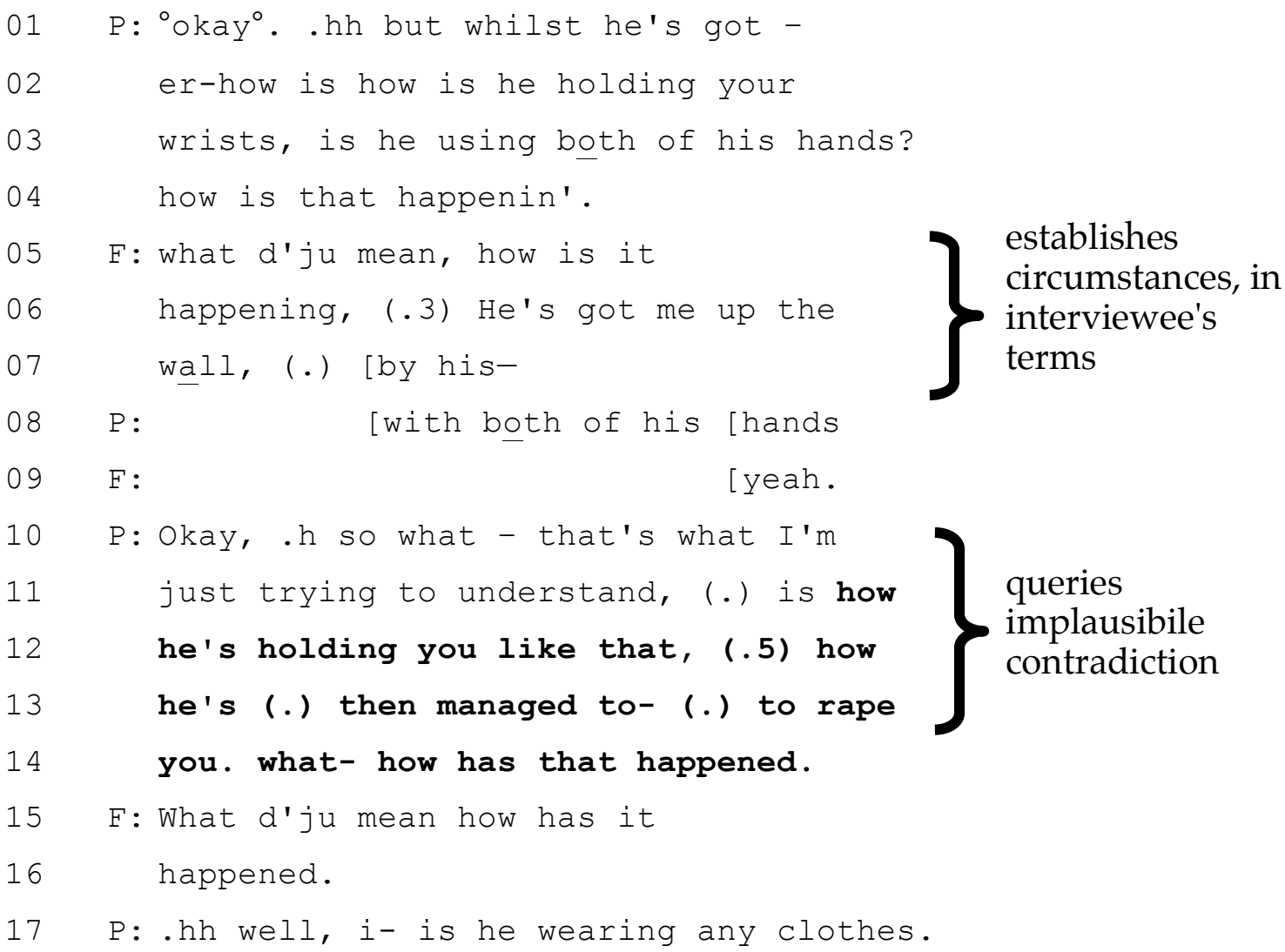

In Extract 2 above, the interviewer (P) first establishes that, according to the complainant $(\mathrm{F})$, the alleged rapist is holding both of her wrists with his hands; she already hints at a doubt (how is that happenin'?), but once the complainant confirms that this is so, the interviewer asks a contrastive, implicitly if-then question [if] he's holding you like that, [then] how's he managed to rape you. To be sure, it is prefaced by the mandated expression of puzzlement (that's what I'm just trying to understand); but it is nevertheless fault-implicative. Note also the use of the verb 'managed', implying that the rapist would have to overcome some difficulty. The effect is to cast doubt on the physical possibility or plausibility of the complainant's account.

We see the same sequence of the interviewer establishing the circumstances, then questioning the account in Extract 3 below. 


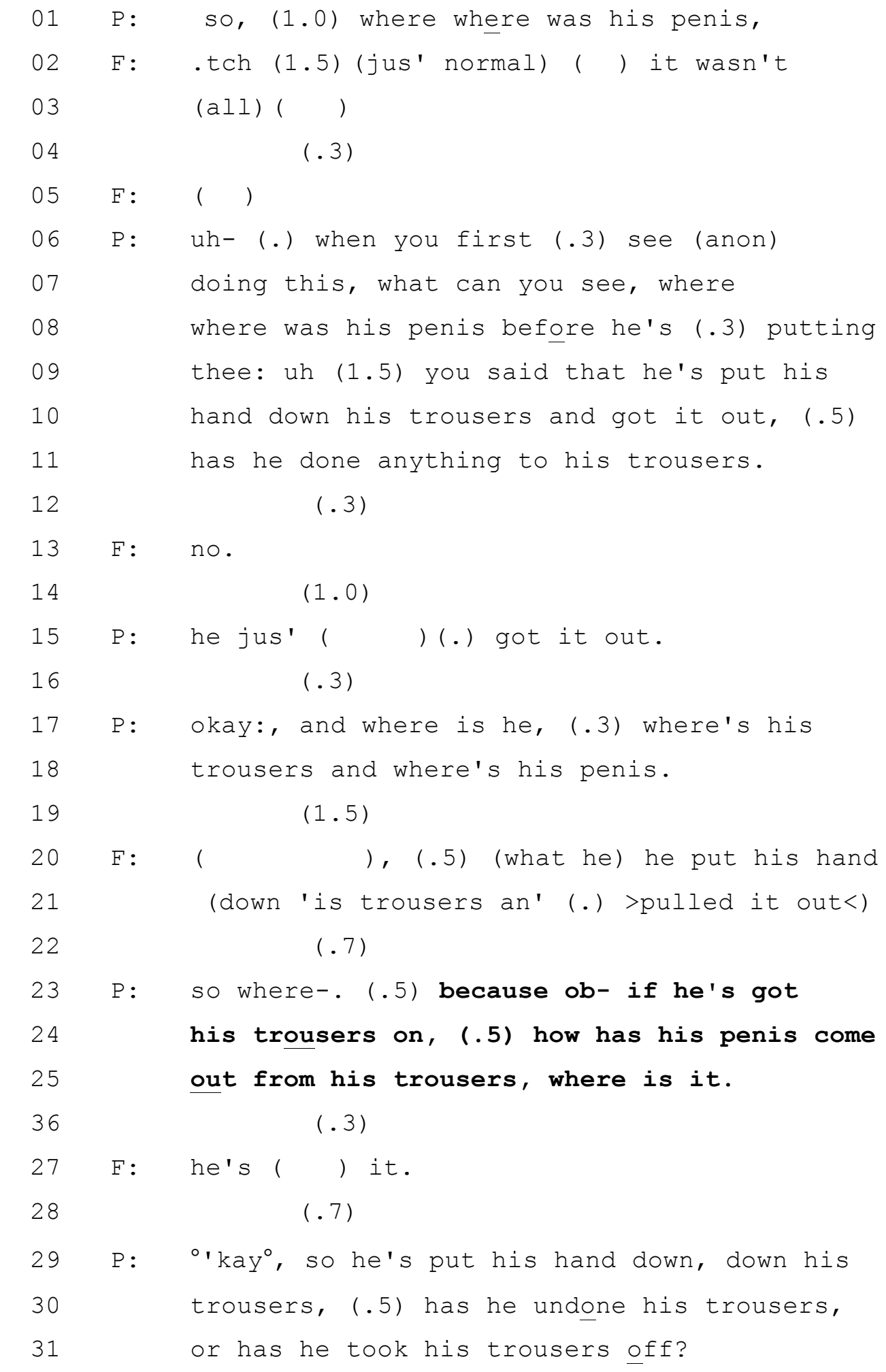

Extract 4 WMP6 Skin to skin

01 P: Whe- (0.8) has he put it- so is i- are your

02 tights and your pants there? 


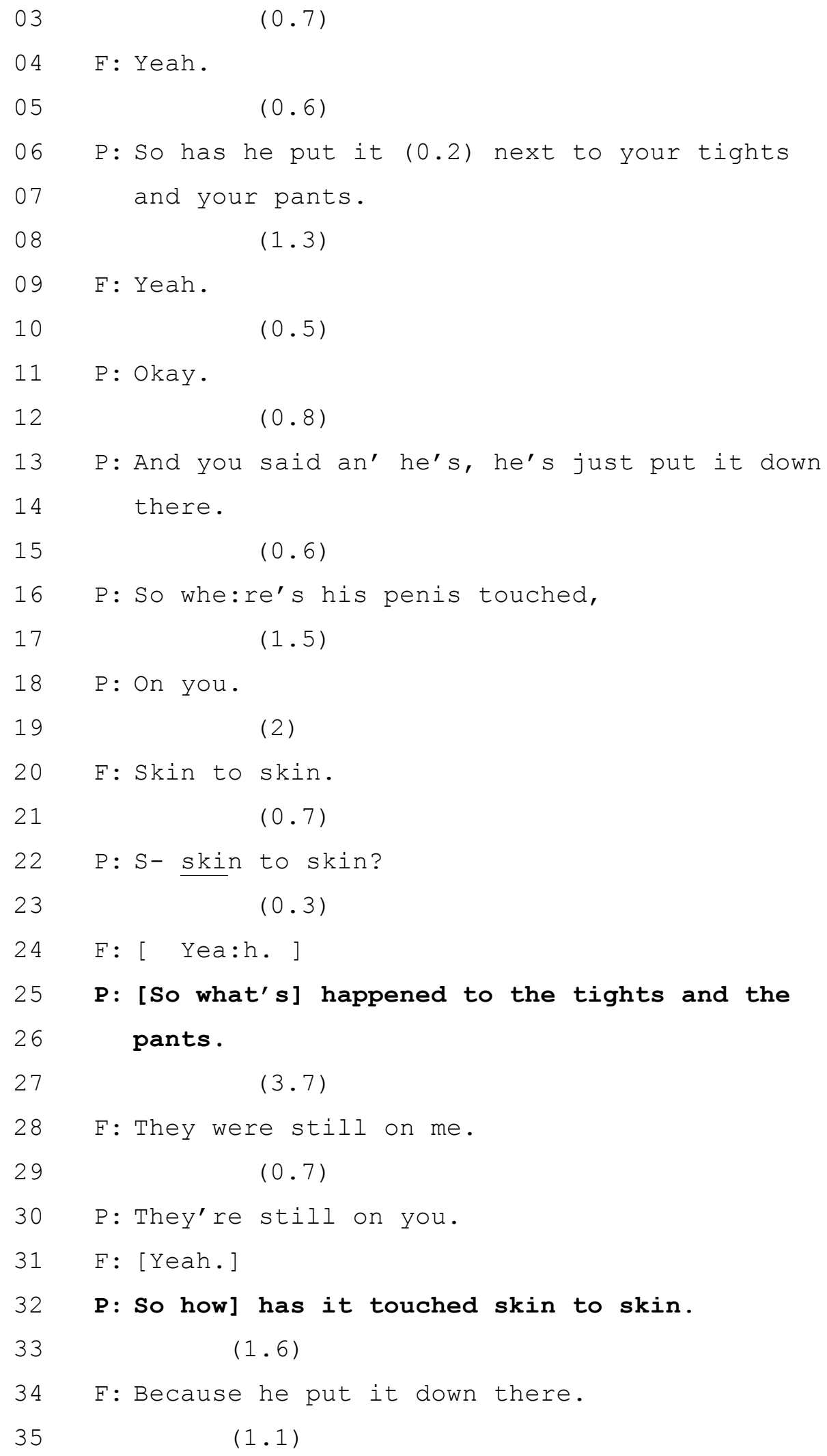

In extract 3 , the interviewer establishes that the man's penis was small and jus' normal - that is, that that it was visible; but that in response to her question has he done anything to his trousers, the interviewer says no (lines 11-13.) She then 
enquires, using the consequential connective $\mathrm{SO}^{2}$, how his penis came out; the pragmatic implication is that the two events are in contradiction - that it would be physically implausible, if not impossible, for the penis to come out if the man had done nothing to the trousers (e.g. pulled them off, opened the flies, undone the zip, etc.). In extract 4, we see the same pattern: P establishes the interviewee's description that the tights and pants are still on her (lines 1-4 and again at 25-26), but also that his penis touched her skin; she then issues a consequential so how... (line 32) implying that it would be impossible or implausible for the man's penis to have touched her 'skin to skin'.

In the last example (below) in this section, we see how being used with the conjunction though.

Extract 5 WMP13 In that position

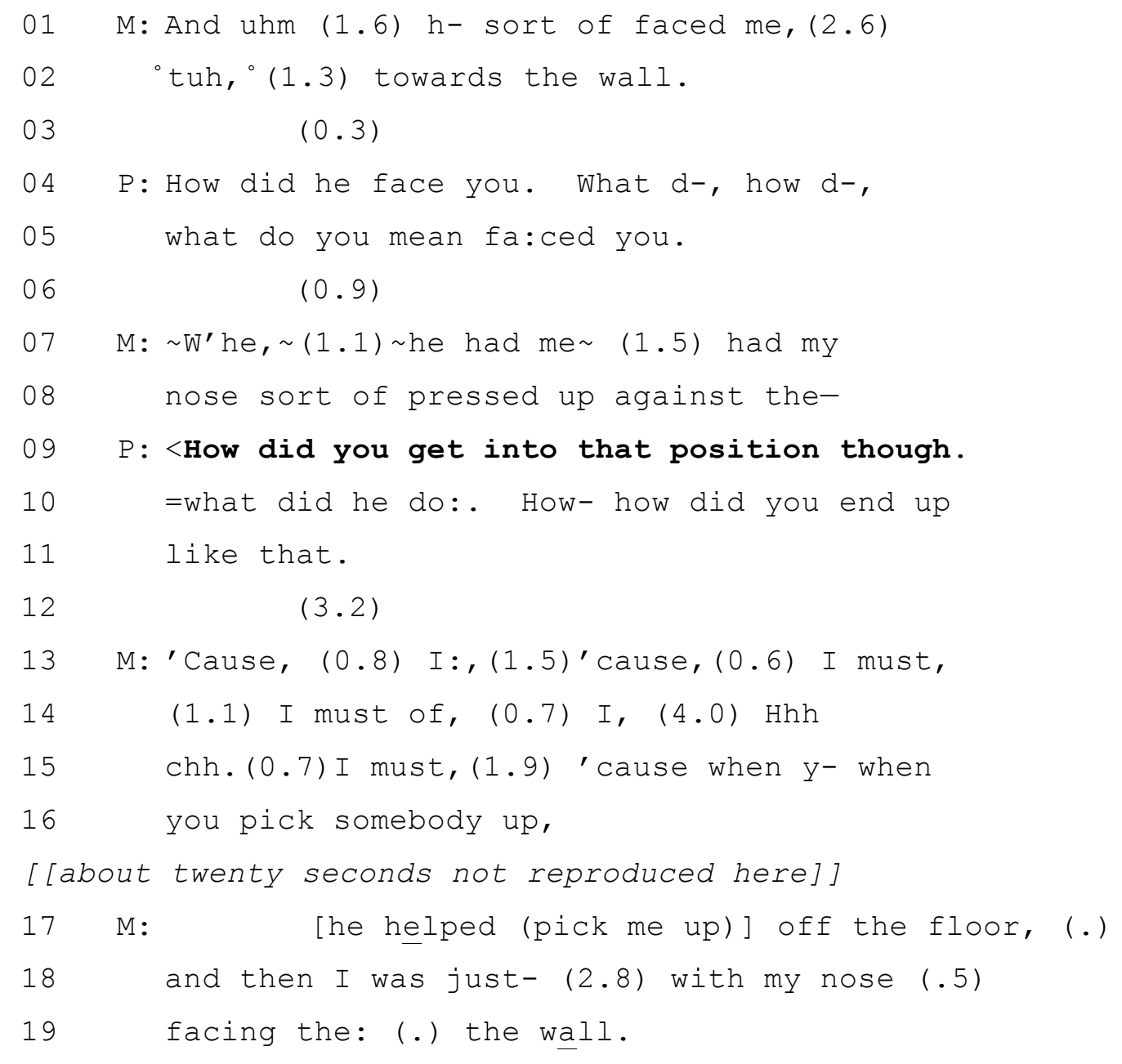

' For the workings of the connective so see, for example, Fraser (1998) 


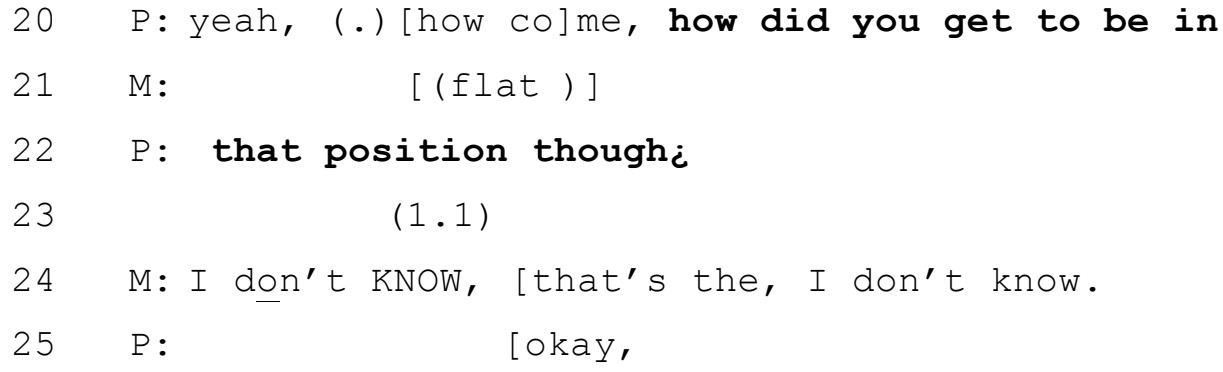

The interviewer here has established that the interviewee has been "faced towards the wall" by the alleged offender. On two occasions, she tries to clarify how this had come to pass; the implication is that the interviewee has missed out a step in the chronology of the action. The use of the contrastive marker though implies a contrastive state of affairs (Fraser, 1998); the implied question is how (nevertheless) did the interviewee get to be in that position, as it were in spite of what he had already said about the matter.

Summary of probes of events.

The evidence for our claim that the how questions above are challenging can, in standard pragmatic reasoning, be seen by imagining the unlikelihood of using this formulation in the opposite case - i.e. where the element of the story being questioned was unchallenging natural and consistent with what had already been established. Consider the following (made-up) sentences, which, though grammatical, seem odd:

- If his hands were free, how was he able to get his penis out of his trousers?

- You were both naked from the waist down, so how was he able to put his penis on you 'skin to skin'?

The strangeness of those unusual formulations reinforces the case that when they are used normally, it is to cast doubt on the naturalness or plausibility of the events queried. We also have interactional evidence that the question was seen as a challenge by the interviewee. Consider these fragments of the extracts we have seen above:

Extract 2 (detail)

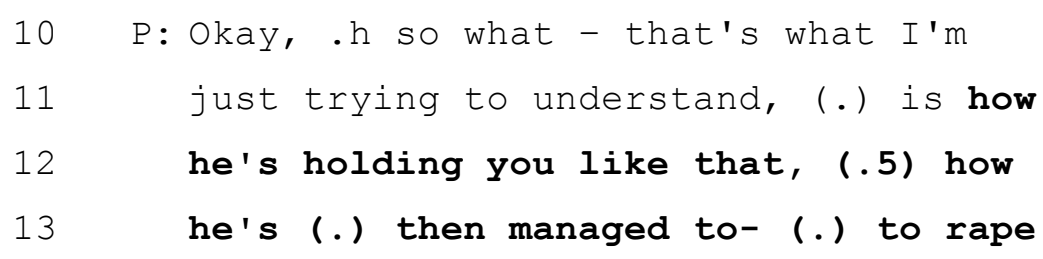




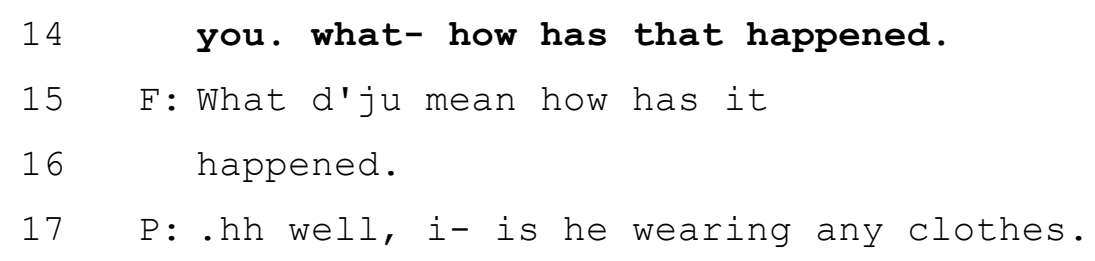

Extract 5 (detail)

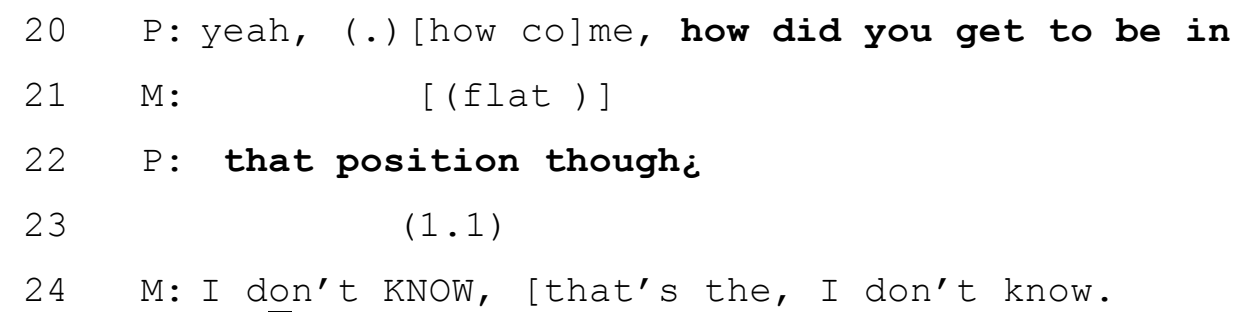

In the two extracts above the interviewee responds to the question in a manner that indicates some kind of resistance or distress. In the first, the reply (lines 1516 ) is not an answer but a question itself (and one that challenges the interviewer's presumptions); and in the second, it is a don't know response (line 24), after a significant gap, and delivered in what on the tape sounds like an anguished cry. In CA terms, both these reactions are 'disaligning' - they frustrate the premises of the question, and represent a halt to the progress of the interaction. Combined with the pragmatic evidence, this looks like good grounds for concluding that the interviewers' probes are indeed challenging.

\section{B. Probes rendering the interviewee's conduct questionable}

In questioning the interviewee's conduct, interviewers used the same sequence as described in section A above: they solicited the interviewee's confirmation of a certain state of affairs, then questioned some aspect of it in a manner that strongly implied its implausibility. Here, the aspect they questioned was the accountable nature of the complainant's behaviour, in the light of the description of events they had just given and confirmed. Interviewers used two interrogative formats - how questions and why questions. We will detail them separately.

\section{i) Questioning conduct with how questions}

In the extract below (6) the complainant is describing the phase of events where, after she and the person who subsequently committed the alleged offence were walking along a footpath, they came to a stop. Note the 
interviewer establishing the circumstances (looking for (Fernando) etc.), before launching a first query with why, and a more pointed one with how come.

\section{Extract 6 WMP6 Stopped at that point}

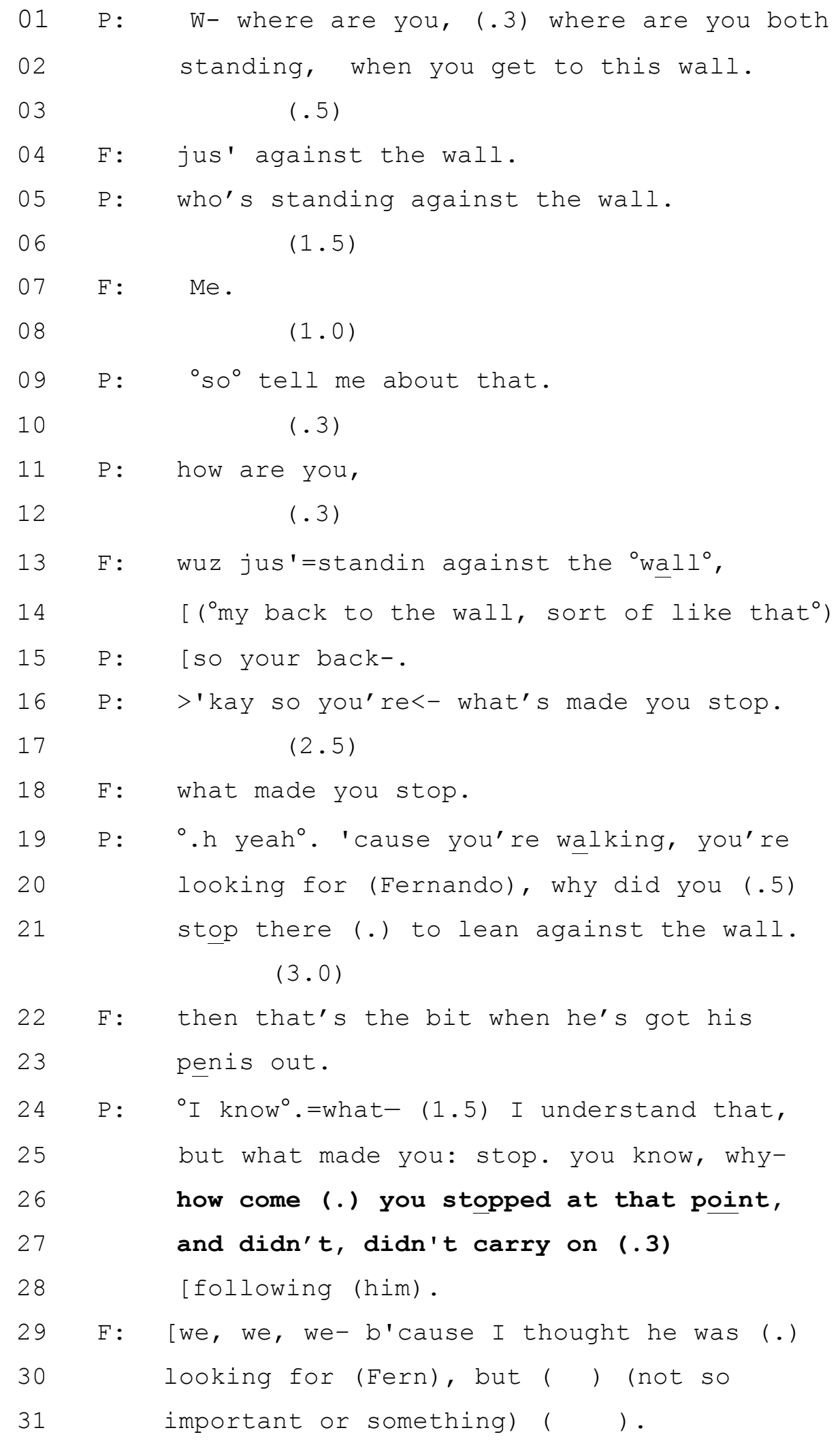


33 P: ${ }^{\circ}$ right ${ }^{\circ}$ (.3) so you've stopped.

The interviewer has solicited confirmation that the interviewee has stopped walking and has 'her back to the wall'. Again we see the interviewer use the mandated expression of puzzlement (in the repaired line 24) before something tendentious: she uses the formulation how come you did $X$ and not $Y$ which very strongly pragmatically implies that $\mathrm{Y}$ was the more reasonable or expectable (perhaps more prudent and reasonable) course of action (see for example Collins, 1991; Fitzpatrick, 2005).

Extract 7 WMP14 All you'd been through

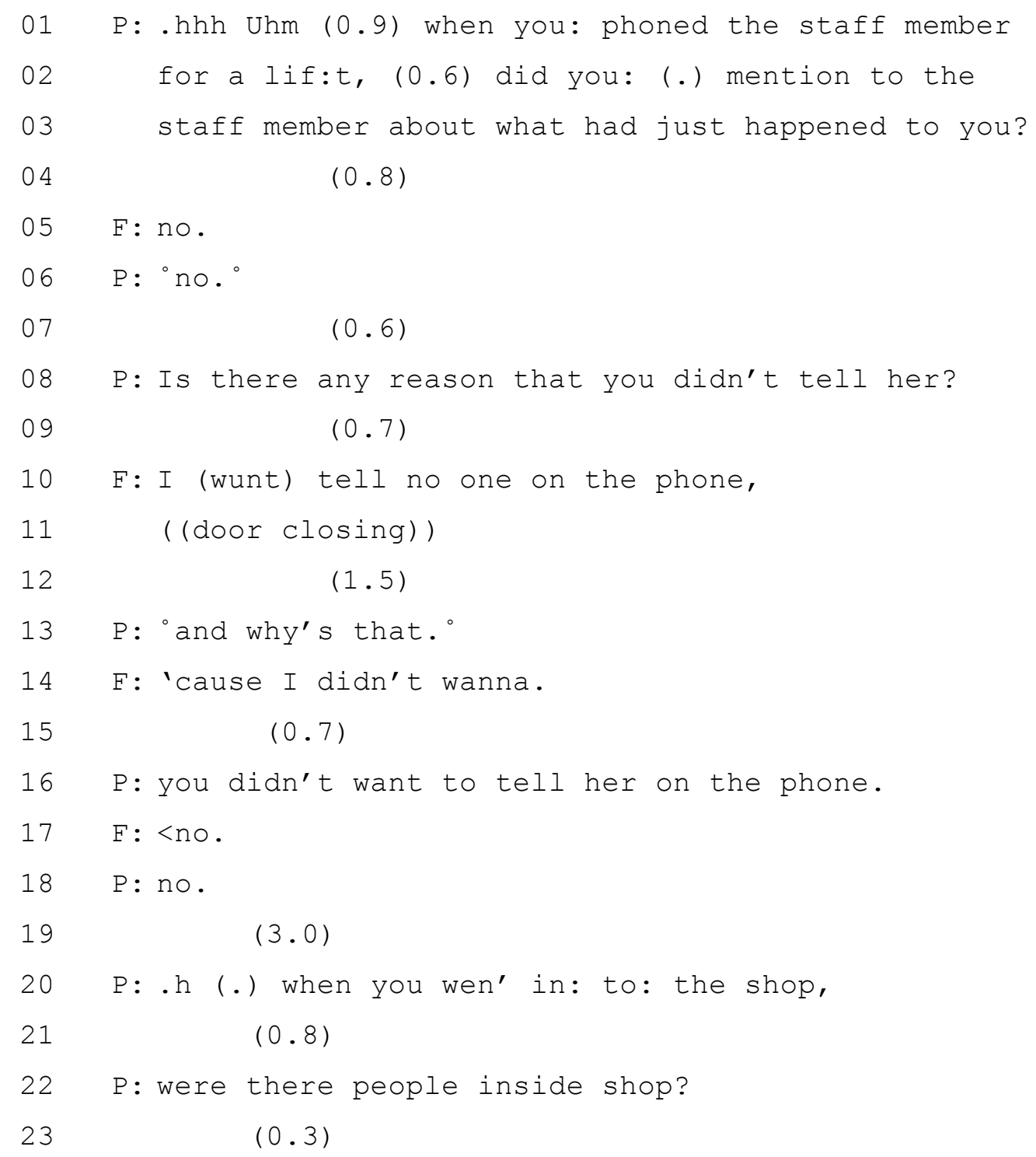




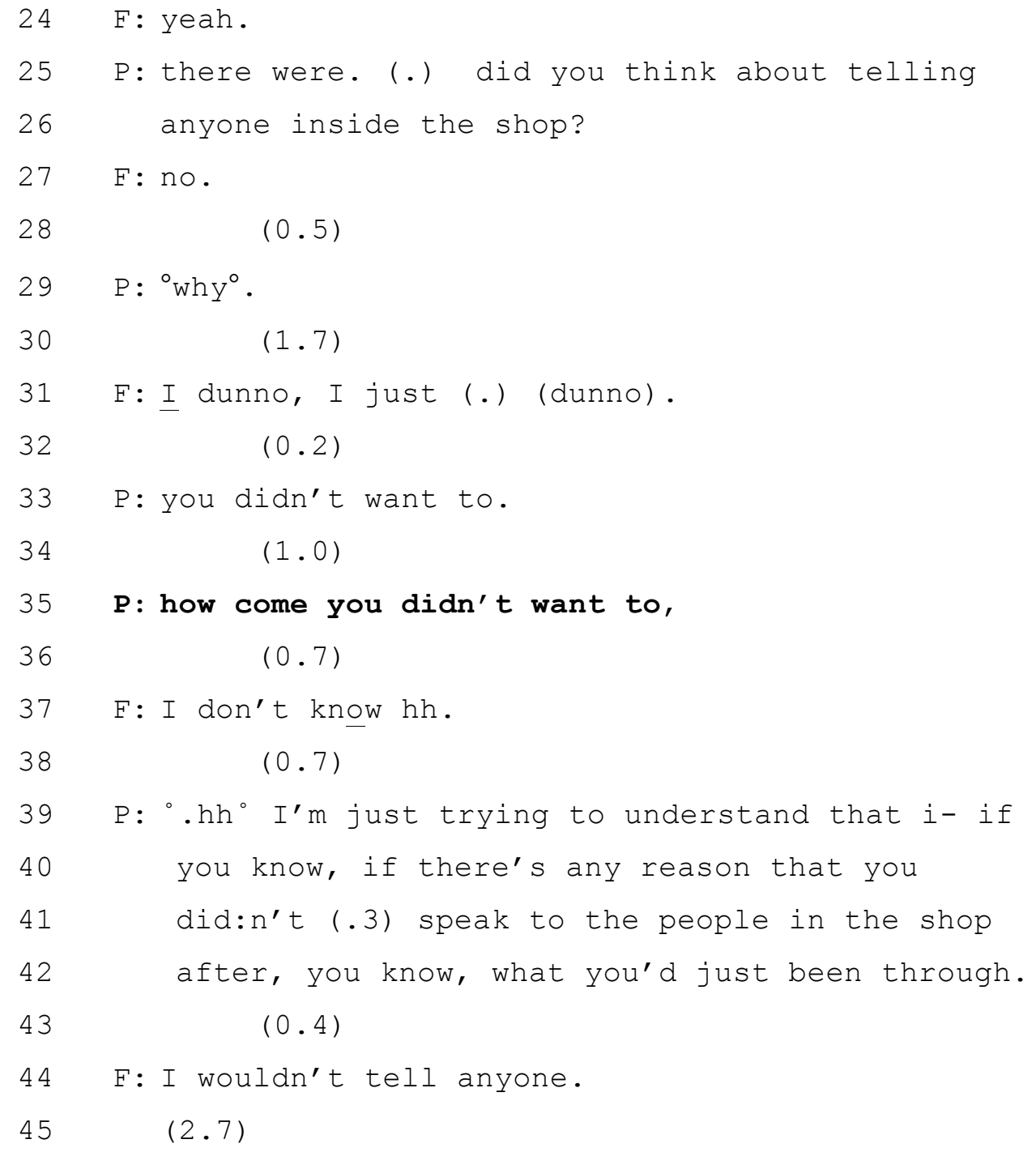

In the lead-up to examining the question how come you didn't want to?, it is worth noting the environment of accountability, to put it no more strongly, that the interviewer has built up in lines 1-30. It would be part of a defence case (or a 'rape myth') were it to be argued that the complainant did not seek help at the very earliest opportunity; hence the question at lines 2-3. The complainant says that she did not do so. Now the accountability is ratcheted up: the interviewer asks: is there any reason why you didn't call her (line 8). The quantifier 'any', as Robinson and Heritage (2014) have shown, is pragmatically directed towards a negative state of affairs: compare the unexceptionable response "I didn't have any reason" versus the odd-sounding "I had any reason"; had the interviewer used the quantifier "some" then it would have allowed the response "I had some reason". "Was there any reason" for not telling a staff member implies that there 
was none; or in other words, that nothing prevented the interviewee from reporting the incident.

The interviewer then establishes that the complainant went into a shop, and that "there were people inside". On this basis she asks whether the complainant told anyone; when the answer is no, she asks baldly why (line 29). To be asked one's motivation for something one did not do is, pragmatically, to imply that one ought to have done it, or that doing it would have been normal in the circumstances; it casts the non-action as not normatively expectable (at least, from the point of view of the questioner). For an interviewee with an intellectual disability, such complexity would be hard to process. Then the interviewer uses the how come format - the strongest form one could use as a presumptive query (here, of what the complainant did not do). Finally (in this stretch) the interviewer makes clear her judgment - albeit using the language of 'trying to understand' recommended by $A B E$ - that the complainant's actions required explanation "after what you had been through".

\section{ii) Questioning interviewees' conduct with why}

As before, the sequence begins with the establishment of a certain state of affairs. However, unlike how questions, what the interviewer then does is not to point to an element of contrast or contradiction in the scene; rather it is to identify it is of some aspect of the conduct (or its absence) that contrasts with what would be normatively expectable. We report on two uses - why did you do $X$ ?, which requires the interviewee to see that $X$ was at least unexpected; and still more pragmatically complex negative format why didn't you do $Y$ ?, which requires them also to a with a state of affairs different from what they have said that they remember.

\section{ii) a. Why did you do / think $X$}

Although not as powerful a challenge as why didn't you do $Y$ ? (which we shall come to below) this form nevertheless claims some element of the interviewee's conduct as being unexpected in the circumstances. As before, the sequence depends on the interviewer establishing a certain state of affairs, then querying the complainant's behaviour against that background. In the case below, for 
example, the interviewer makes a point of restating the operative part of the narrative as a preface to her question.

Extract 8 WMP20 It's midday

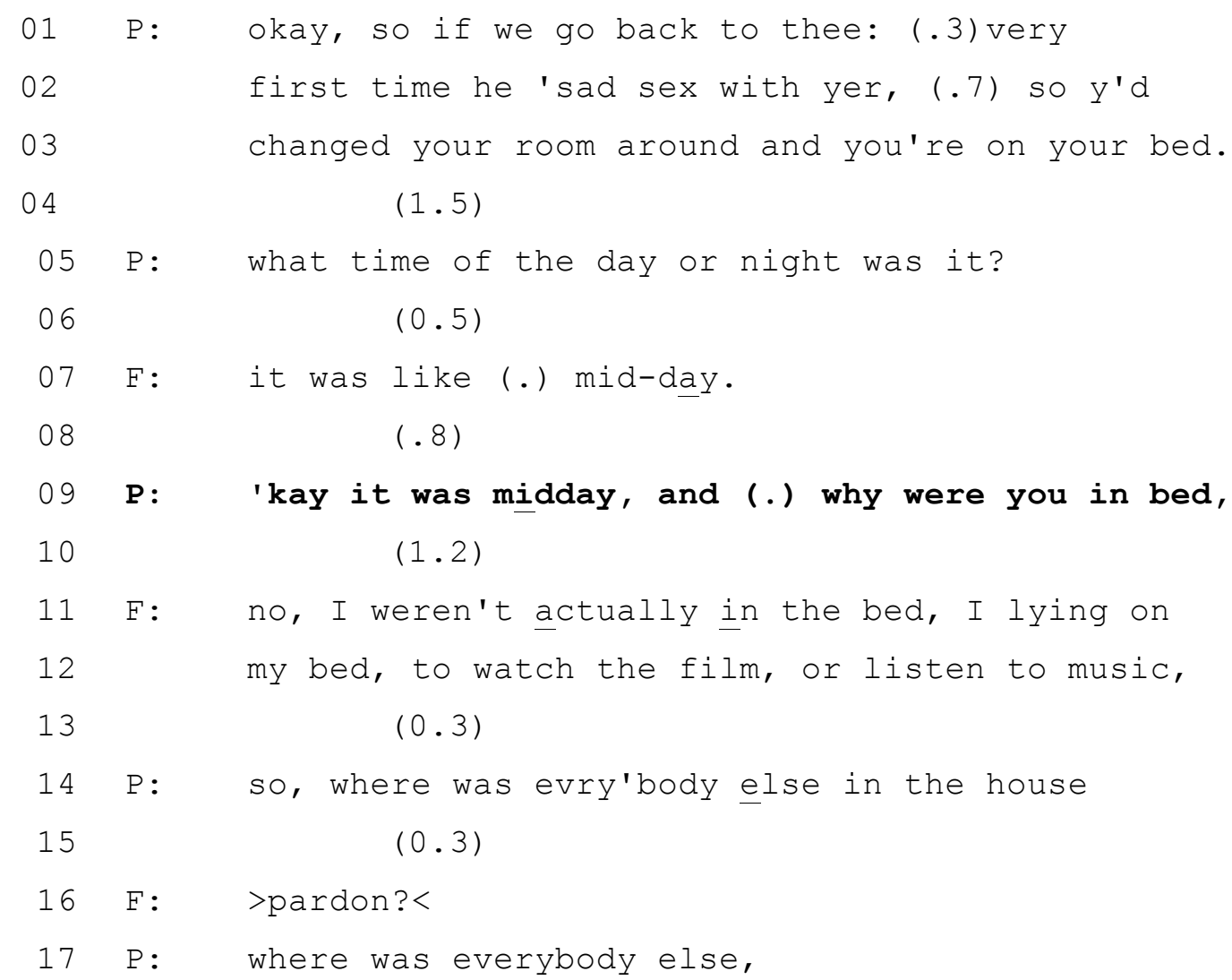

The interviewer repeats it's midday and use the conjunction and to imply that there is a connection between that and the behaviour in question; presumably against the common-sense presumption that people are normally long out of bed by that time. The implication is of some (unstated) "lifestyle" failing; not technically relevant to the case, but potentially damaging to the complainant's general credibility, and the kind of issue that would be picked up in crossexamination in court.

ii) b. Why didn't you do Y?

This is a format which is difficult for the person with ID in two ways. It requires them to process a counterfactual (something that didn't happen) and to see that it very strongly implies blame. Counterfactual reasoning is difficult for children and adults with low IQ; it requires them to conjure events that are not present 
in memory, and are in fact contrary to what they recall (see, for example, Robinson and Beck, 2000). In terms of blame, as Bolden and Robinson (2011) point out, following Schegloff (1988), "negative formatting (e.g., Why didn't you say hello?) can be a practice for formulating someone or something as a failure, which can independently accomplish complaining and criticizing." (Bolden and Robinson (ibid p 98). In the case below, the implied failure is not fighting off the assailant.

Extract 9 WMP 3 Have you screamed (\#=creaky voice)

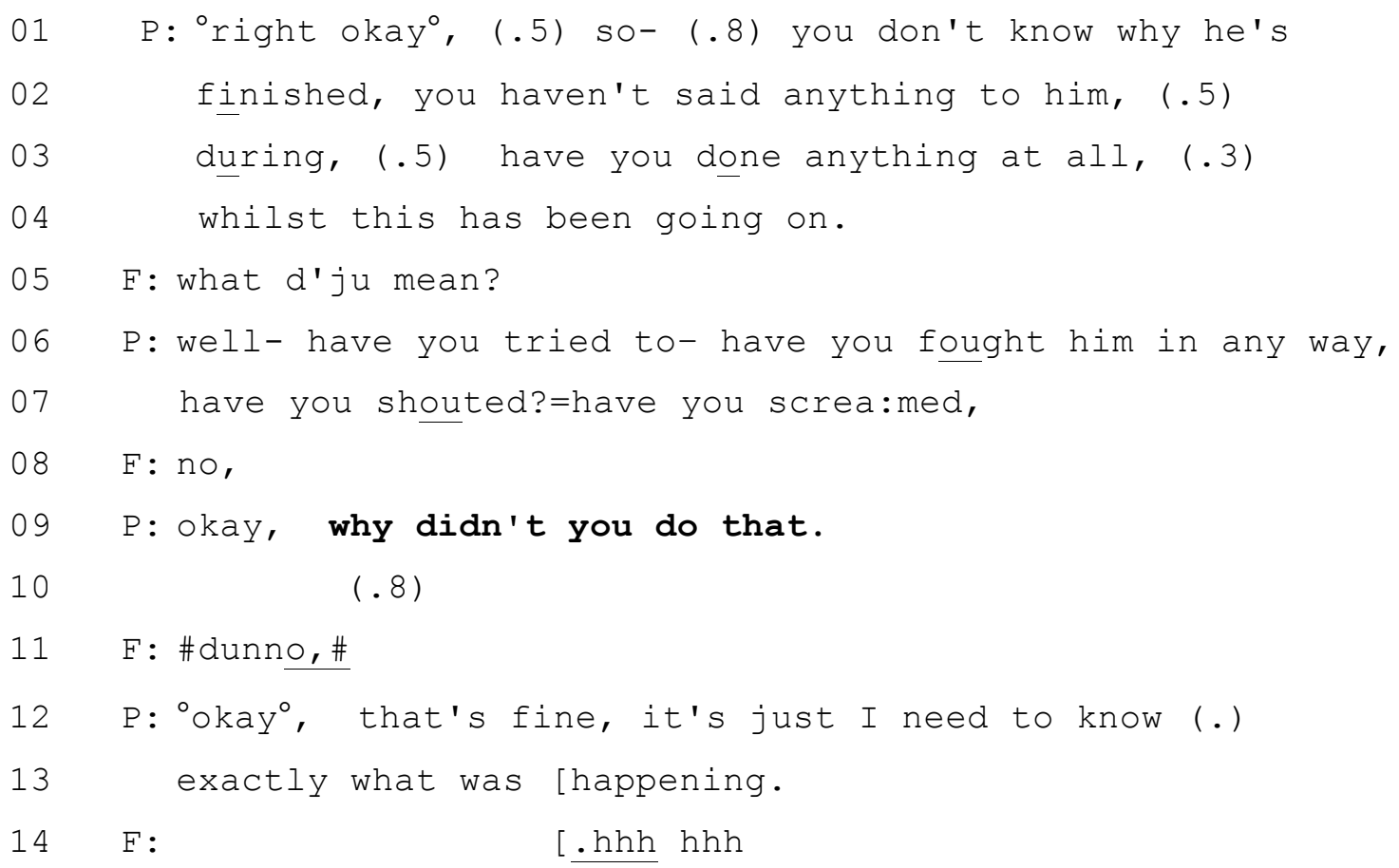

Multi-unit questions can have many functions (Svennevig, 2013), but here they accumulate a list of alternative actions all of which would be expectable in the circumstances, but none of which have so far been reported by the interviewee. The interviewee confirms that she did none of them; the interviewer receipts this confirmation, and asks why didn't you do that? The use of 'that' treats all the options as effectively adding up to one thing (presumably 'fight him off' or 'make some protest'), the absence of which the question marks and treats as accountable. 
In Extract 10 below, the interviewer gives a summary of the interviewee's narrative at that point, and invites her to explain why she did not take what is construed to be to be an obviously prudent course of action.

Extract 10. WMP 14 Walk away

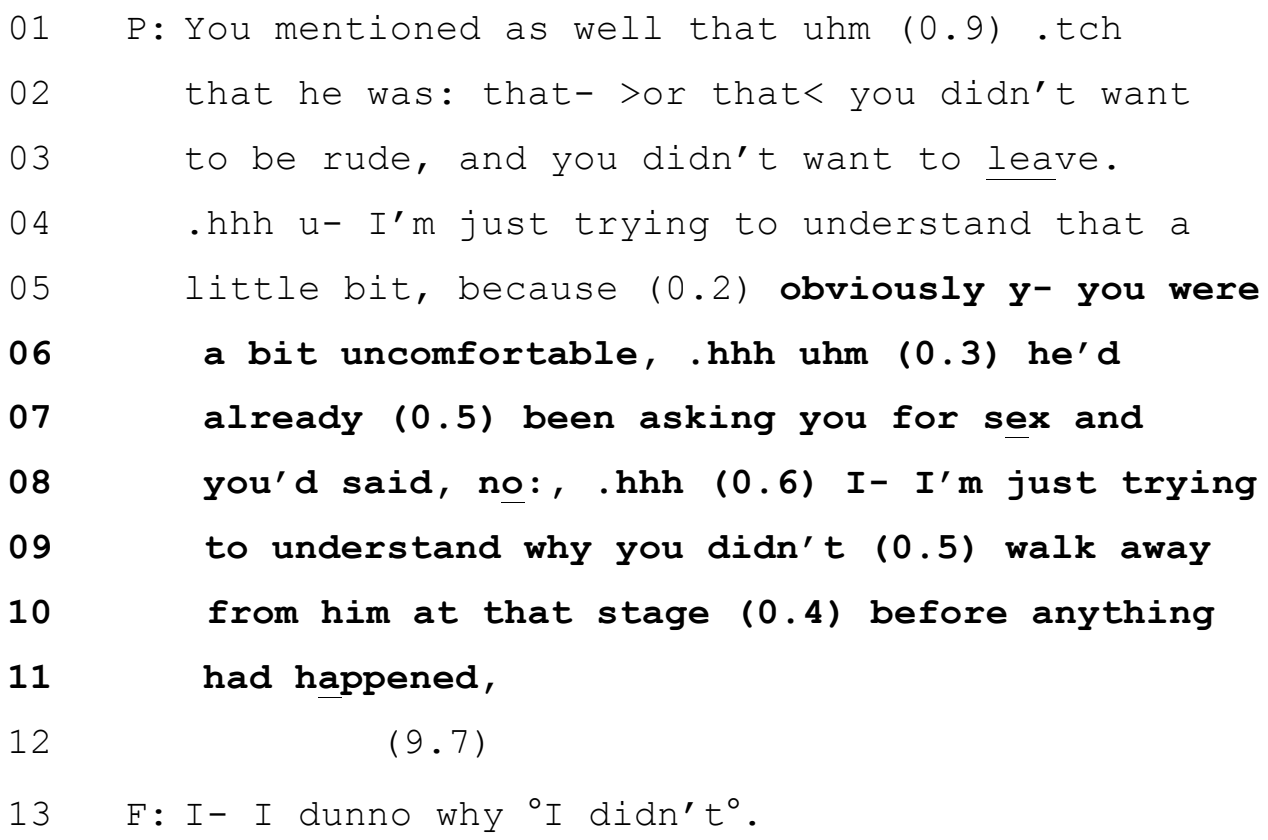

Having established that the complainant was uncomfortable being on to the canal bank with the man, given that she'd already refused one request for sex, the interviewer then probes further, using the $A B E$ format of expressing her need to understand. But what she needs to understand is cast as an accountable failure (given $Y$, why you didn't do X?). The interviewee is reminded that she was already feeling uncomfortable, and she'd already refused the mean's request for sex; hence she is asked why [she] didn't walk away from him at that stage, before anything had happened. Although the interviewer presents this in the approved $A B E$ manner as a matter of her 'trying to understand', the interviewee treats it as a question - to which she has no answer. Again, this might arguably be because, for an interviewee with an intellectual disability, the complexity of this sort of counterfactual is hard to process. One way or another, it leaves her open to the accusation (were this to be repeated in a courtroom cross-examination) of being either too vague about the events, or, worse, admitting not having been sufficiently prudent. But, again, the question 
requires understanding a counterfactual, which may test someone with limited cognitive abilities.

Summary of challenges to the interviewee's behaviour

As we did with questions about events, we need to back up our claim that the interviewers' questions about conduct are challenging. We can apply the same pragmatic reasoning here, and imagine the unlikelihood of using hows and whys about behaviour in the opposite case - i.e. where what is being queried was not risky, unreasonable and so on. Consider the following (made-up) sentences, which, though grammatical, seem odd:

- How come you asked people nearby for help when you were being threatened?

- Why did you scream and fight when he was trying to rape you?

The oddity of such questions is evidence that they are normally only used when the behaviour they query is socially understood to be worthy of an explanation. The further evidence we have that these are challenges comes form the way that they are responded to by the interviewees. Consider these responses, taken from the extracts presented above:

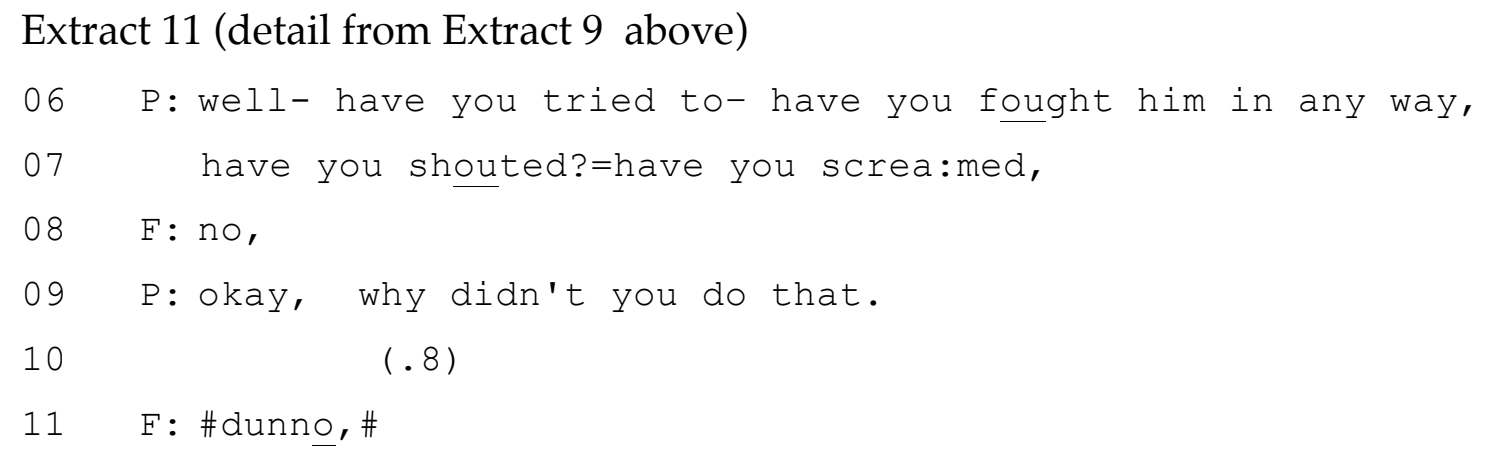

Extract 12 (detail from Extract 10 above)

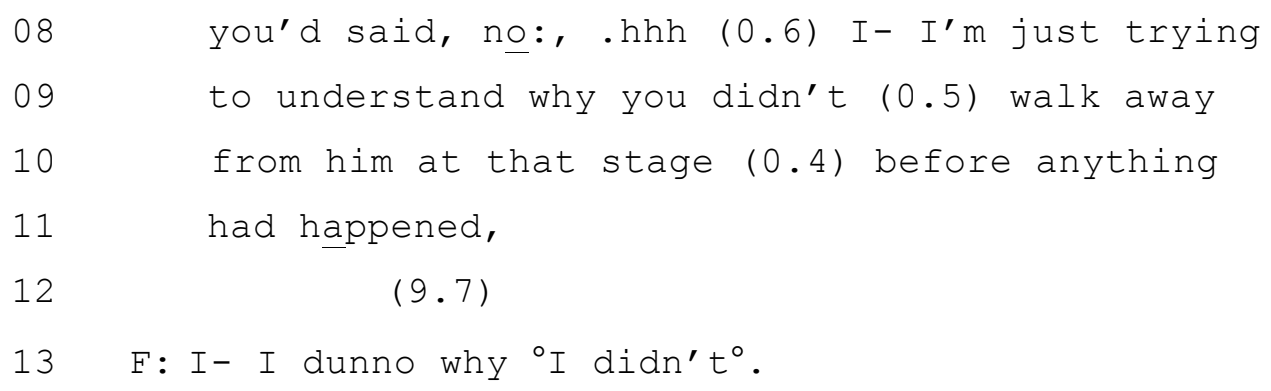

In both cases, the interviewee responds with I don't know. Declaring that one does not know the answer to a question is not necessarily a sign of anything 
untoward; but here the question is about the interviewee's own conduct, about which she would be expected to have full knowledge (she would be expected to have what CA calls epistemic authority - see Heritage, 2012). Hence not knowing comes across as an admission of failure.

\section{Discussion}

People with intellectual disabilities struggle with language, and especially with its pragmatic implications. Pragmatically complex questions in such a charged environment may cause the interviewee some distress (as is indicated in Extract $5^{2}$ ) and, more consequentially for the judicial process, may distort the account they are able to give of their experiences. Not only might they simply not understand the question, but they might give an answer that failed to deal with the fault that it implied. Thus, for example, if the question is predicated on something that "anyone" would do (for example, shout and scream if attacked, as in Extract 11)), one could reply in a way that offered a countervailing account (for example stating explicitly that you were physically restrained, or feared further escalating the danger and so on). Not doing so - saying dunno as the complainant did in Extract 11, leaves the implication hanging that one did not do the 'reasonable' thing. And, perhaps, damaging your credibility and further implying that the events were not all quite as you reported.

Our aim in this paper was to examine a sample of UK police officers' interviews with intellectually disabled complainants alleging sexual assault, and compare the way they probe accounts with what is mandated in Ministry of Justice guidelines. Much of the interviewers' questioning is indeed in line with the guidelines. But although the guidelines explicitly warn against "why' questions which imply blame, we found that these were in fact used, at some point, by most interviewers. When the interviewee was asked to explain what didn't happen (why didn't you ...), then the pragmatic effect of implying fault was still more evident. Other formats too had this effect: the guidelines do not mention "how...." or "so how...."questions, nor "if" or "if/then" questions - but these too were used, with the same pragmatic consequences.

'In fact, the interviewees were generally self-composed; for how the interviewers dealt with their occasional expressions of distress, see Antaki et al, (2015) 
What $A B E$ says about "why" questions is instructive:

3.50 A question beginning with 'why', although it may produce a response, can create more problems than it solves, particularly if the question seeks an explanation of behaviour. ... 'why' questions also tend to promote the feeling of blame. Victims often partly blame themselves for what happened and so 'why' questions may strengthen this belief. This will not help the witness or the remembering process. [emphasis added]

Evidence from pragmatics and interactional analysis, however, puts the case for 'blame' more strongly, and independent of participants' mental states. It is a matter of the conventional meaning of these ways of putting questions. As Bolden and Robinson put it: "Why-formatted interrogatives display a challenging stance toward the accountable event and responsible agent(s) and are, thus, frequently co-implicated in complaining, criticizing, and blaming." (Bolden and Robinson, 2011, p. 94). Indeed, Bolden and Robinson observe, following Koshik (2005), that Koshik (2005) argued that, when "why -and how come ... are asked... from a position of epistemic strength (i.e., about something that the questioner has more rights to know about) wh -interrogatives can function as ... assertions that accomplish challenging/complaining rather than questioning" (Bolden and Robinson, p 97). Moreover, "negative formatting" (e.g., Why didn't you say hello? ) can, as Schegloff (1988) has shown, be a practice for formulating someone or something as a failure.

There are many contributory reasons for why the interviews (at least sometimes) turn out this way. The probable immediate explanation for the interviewers' deviation from best practice, as enshrined in the $A B E$ guidelines that they have been trained in, is that they face a well-known forensic dilemma. They have both to establish an account of the episode as expressed in the interviewee's own words, but also to make sure that the account is free from inconsistency, vagueness, or implausibility. The tape is made specifically to stand as 'evidence-in-chief' to be played to the court; this means that there is a risk that any perceived difficulty about the victim's account, left unexamined on the tape, would be exploited by defence counsel. Hence there is a premium on making the victim's account as satisfactory as possible. 
But what is 'satisfactory'? All but two of the 19 complainants were women or girls, so it would be arguable that at least some of the criteria of 'satisfactoriness' they were subjected to were 'rape myths' that women routinely face (as MacLeod, 2010 graphically illustrates in a study of police interviews of a small number of women with typical cognitive abilities). We have held off pursuing that line, in favour of emphasising not the complainants' gender but their intellectual disability, on the basis that the relation between limited language comprehension and the pragmatic complexities of tendentious questions is obvious in the scene, and is immune to objections (as a gender argument would be) to the criticism of small numbers and comparison groups. Of course, the two lines of argument are perfectly consistent, and it might well be that women who have an intellectual impairment are even more likely to be doubted than those who are cognitively typical - we don't have the evidence to say. One way or another, the motivation for the police interviewer is the same: if a doubt (well-founded or not) begins to form in their mind, they might (as happened in the cases documented in the examples in this article) pursue what they consider to be implausible detail, or imprudent behaviour, in the challenging way that they foresee defence counsel doing.

As corroborative evidence, it is be notable that challenging questioning was wholly lacking in only two of the interviews we studied. In one, the offence was comparatively minor (an unwanted kiss at a bus-stop) and the police interviewer could probably very quickly conclude that the case would not be pursued by the CPS, on the basis that it would not be in the public interest to do so. In the other, the complainant was articulate and clear, the perpetrator already located, and - from the internal evidence of the tape - significant progress in the case already made. In other words, in both cases the dilemma was apparently resolvable without the need to issue challenging questions.

The recommendation that might be derived from the case we have made here always bearing in mind that this is based on a small sample, from one UK police force - is that interviewers do two things in the "probe" phase of their interviews. One is to make it clear, as early as possible, and certainly before any questions of the why didn't you do X? or how come you didn't do Y? type - that 
some upcoming questions might seem to challenge the interviewee's account in a seemingly hostile manner; and to explain why this is so. We acknowledge that this may not be an easy matter when the complainant's intellectual disability hinders understanding, but the alternative - of these questions seeming to be actually hostile - is to be avoided at all costs. The other recommendation is to avoid the formulations why didn't you do X? and how come you didn't do Y?, and their variants. That this is possible is evident from the other means of questioning that the police officers themselves use, indeed in the same interviews. Proving a case against later challenge need not, in itself, be challenging. 


\section{References}

Antaki, C., Richardson, E., Stokoe, E and Willott, S. (2015) Dealing with the distress of people with intellectual disabilities reporting sexual assault and rape. Discourse Studies, 17, 1-18

Bolden, G and Robinson, J (2011) Soliciting Accounts With Why-Interrogatives in Conversation. Journal of Communication, 61, 1, 94-119

Collins, C. (1991). Why and How Come. In L. Cheng and H. Demirdache (eds.), More Papers on Wh- Movement, MIT Working Papers in Linguistics 15. (pp. 3145)

Ehrlich, S (2001) Representing Rape: Language and Sexual Consent. London: Routledge

Fitzpatrick, J (2005) The Whys and How Comes of Presupposition and NPI Licensing in Questions. In John Alderete, Chung-hye Han, and Alexei Kochetov (Eds) Proceedings of the 24th West Coast Conference on Formal Linguistics, . Somerville, MA: Cascadilla Proceedings Project. pp 138-145

Fraser, B (1998) Contrastive discourse markers in English. In A H Jucker and Y Ziv (eds) Discourse Markers. Amsterdam: John Benjamins pp 301-326

Frohmann, L (1991) Discrediting Victims' Allegations of Sexual Assault: Prosecutorial Accounts of Case Rejections. Social Problems, 38 213-226

Heritage, J. (2012). The epistemic engine: Sequence organization and territories of knowledge. Research on Language and Social Interaction, 45, 25-50.

Jaszczolt, K M and Allen, K (2012) Introduction: pragmatic objects and pragmatic methods. In K Allen, and K M Jaszczolt, (eds) The Cambridge Handbook of Pragmatics, Cambridge, pp 1-19 
Koshik, I. (2005). Beyond rhetorical questions: Assertive questions in everyday interaction. Philadelphia: John Benjamins.

Lea, S., Lanvers, U. \& Shaw, S. (2003) Attrition in Rape Cases: Developing a Profile and Identifying Relevant Factors, British Journal of Criminology, 43, 58399.

MacLeod, N. J. (2010) Police Interviews with Women Reporting Rape: A Critical Discourse Analysis Unpublished PhD thesis, School of Languages \& Social Sciences, Aston University. < http: / / eprints.aston.ac.uk/15206/> Accessed 18 October 2014

McEachern, A. G. (2012). Sexual abuse of individuals with disabilities: Prevention strategies for clinical practice. Journal of Child Sexual Abuse, 21(4), 386-398,

Perkins, M (2010) Pragmatic impairment. In J. S. Damico, N Müller and M J Ball (eds) The Handbook of Language and Speech Disorders. Chichester: Blackwell.

Robinson, E. J. and Beck, S (2000) What is difficult about counterfactual reasoning? In P Mitchell and K Riggs (eds) Children's reasoning and the mind. Hove: Psychology Press , pp 101-120.

Robinson, J. D., \& Heritage, J. (2014). Intervening with conversation analysis: The case of medicine. Research on Language and Social Interaction, 47, 201-218.

Rowsell WL, Clare ICH and Murphy G (2012) The psychological impact of abuse on men and women with severe intellectual disabilities. Journal of Applied Research in Intellectual Disabilities, 26: 257-270.

Royal College of Psychiatrists (2014). Forensic care pathways for adults with intellectual disability involved with the criminal justice system. London: Royal College of Psychiatrists

Schegloff, E. A. (1988). Goffman and the analysis of conversation. In P. Drew \& 
A. J. Wootton (Eds.), Erving Goffman: Exploring the interaction order. Cambridge, U.K.: Polity Press (pp. 89-135)

Sidnell, J (2010) Conversation Analysis: An Introduction Chichester: WileyBlackwell

Spohn, C and Tellis, K (2014) Policing E Prosecuting Sexual Assault: Inside the Criminal Justice System. US Department of Justice / Rienner Publishers

Svennevig, J (2013) Reformulation of questions with candidate answers. International Journal of Bilingualism, 17, 189-204

UK Ministry of Justice (2011) Achieving Best Evidence in Criminal Proceedings. London: HMSO http: / / www.justice.gov.uk/downloads/victims-andwitnesses / vulnerable-witnesses / achieving-best-evidence-criminalproceedings.pdf [accessed June 2014]

US Bureau of Justice Statistics (2014). Crime Against Persons with Disabilities 2009-2011 Statistical Tables.

http: / / www.bjs.gov / content/pub/pdf/ capd0912st.pdf [Accessed 25 July 2014] 


\title{
Transcription Symbols
}

\author{
(. ) Just noticeable pause \\ $(.3),(2.6) \quad$ Examples of timed pauses \\ word [word \\ [word The start of overlapping talk. \\ . hh, hh In-breath (note the preceding full stop) and out-breath respectively. \\ wo $(\mathrm{h}) \mathrm{rd} \quad$ (h) shows that the word has "laughter" bubbling within it \\ wor- \\ wo: $r d$ \\ A dash shows a sharp cut-off \\ (words) \\ Colons show that the speaker has stretched the preceding sound. \\ $(\quad)$ \\ A guess at what might have been said if unclear \\ word $=$ \\ =word \\ Very unclear talk. \\ word, WORD \\ No discernible pause between two sounds or turns at talk \\ ${ }^{\circ}$ word $^{\circ}$ \\ Underlined sounds are louder, capitals louder still \\ $>$ word word $<$ \\ Material between "degree signs" is quiet \\ $<$ word word $>$ \\ Faster speech \\ word? \\ Slower speech \\ Question mark shows marked upward intonation \\ wordi \\ Upside-down question mark shows slight upward intonation \\ $\rightarrow$ \\ Analyst's signal of a significant line \\ ( (wailing) $\quad$ Attempt at representing something hard, or impossible, to render \\ phonetically
}

